\title{
PARENTAL ROLE IN CHILDREN'S SPORTS ACTIVITIES IN THE CONTEXT OF ACHIEVEMENT GOAL AND SELF- DETERMINATION THEORIES
}

\author{
Enrika Kromerova \\ Lithuanian Sports University, Kaunas, Lithuania
}

\begin{abstract}
Background. Aiming at understanding what influences youth sports experiences, researchers emphasize the significance of the role of the family not only in the decision to get engaged in sports activities, but also in the inclination to continue the activities. The increasing emphasis is on parental involvement and the impact of positive and negative verbal behaviour influence on the psychosocial state of children engaged in sport. The aim of this article was a conceptual overview of the family role, as the most significant microenvironment, in children's sports activities.

Methods. Analysis and discussion of scientific literature.

Results. Parental behaviour entails different reactions of children engaged in sports, but on the basis of selfdetermination and achievement goal theories, it can be argued that the behaviour of the family should encourage athletes' mastery orientation, and consequently, a more pro-social conduct and moral reasoning can be expected.

Conclusions. Systematic literature review showed that both theories are in favour of actions and strategy, with reference to parents' encouragement to involve children in a task, while reducing their ego functioning. It can be concluded that parents perceive their behaviour differently from that of their children, so often parents' positive reinforcement can have a negative impact on athletes' psychosocial state, values, behaviour and goal-setting at present and in the future.
\end{abstract}

Keywords: sport, athletes, achievement goal theory, self-determination theory, parents' influence.

\section{INTRODUCTION}

$\mathrm{S}$ port in today's society is a popular, promoted and strongly established activity in which people of any age, social status, or different interests are engaged. Millions of young people around the world are involved in sports activities, and later, in competitive or professional sports, which, supposedly, have a positive impact on adolescent psychosocial development and propensity to exercise at a late age (Elliott \& Drummond, 2016). In addition, sports is treated as an educational tool, shaping children and adolescents' behaviour patterns (Leo, Sánchez-Miguel, Sánchez-Olivia, Amado, \& Garcia-Calvo, 2015) and value orientations, which lay the foundations for pro-social or anti-social behaviour expression not only in sports, but also in other areas of social life. Sports researchers (Elliott \& Drummond, 2016., Leo et al., 2015; Schwebel, Smith, \& Smoll, 2016) aim at establishing what influences young people's experiences in sports and they emphasize the significance of the family role not only in the decision making to be engaged in sports activities (Timperio et al., 2013; Wheeler, 2012), but also in the inclination to continue the activities (Yesu \& Harwood, 2015). Family role usually includes the necessary financial, logistic and emotional support, which gives the child the opportunity to be engaged in sports activities and to develop their physical abilities. Apart from that, more and more emphasis is put on the effect 
of parental involvement (Knight, Dorsch, Osai, Haderlie, \& Sellers, 2016; Stefansen, Smethe, \& Strandbu, 2016; Yesu \& Harwood, 2015) as well as positive and negative verbal behaviour on the psychosocial state of children engaged in sports activities. Research on microclimate created by coaches, parents and other important persons to athletes is based on a number of different theories: Achievement Goal Theory (AGT; Nicholls, 1989) and Self-Determination Theory (SDT; Deci \& Ryan, 1985), which define the type of motivation according to personal goal setting and source of its derivation.

According to Shields and Bredemeir (2007), involvement in sports activities does not necessarily mean a positive impact on the formation of character, but it is unanimously recognized that exercising is an important social experience that can be useful under the right circumstances (Leo et al., 2015). Therefore, it is important to reveal the role of the family in children's sports activities as the most significant microenvironment factor and to answer the question - how parents' behaviour influences children's well-being in sport. Given the dearth of research on this topic, I felt it important to examine this topic in an attempt to provide knowledge that could be useful to educators, physical education teachers and parents.

\section{METHODS}

This review presents a synthesis of research conducted by the author. These methods were used to achieve the research aim: analysis and discussion of scientific literature.

\section{RESULTS AND DISCUSSION}

AGT-based studies have shown that significant surrounding people can have a social impact on the person's needs, expectations and awards (Chan, Londsdale \& Fung, 2011). It should be noted that AGT focuses on two achievement motivation sources: mastery orientation, which is related to the pursuit of personal independence, commitment, systematic demonstration of effort, skill and purposefulness of the task (Leo et al., 2015). Mistakes are regarded as personal growth and self-improvement opportunities (O'Rourke, Smith, Smoll, \& Cumming, 2014), thus, young athletes with a mastery orientation can perceive themselves as having less talent or ability, but still feel successful and competent (Schwebel et al., 2016). Meanwhile, performance orientation is related to competitiveness, the one's self-elevation, demonstration of power and force, often, disregard of rules and regulations, and purposefulness of the ego. Mistakes are unacceptable, and while making every effort to show the best performance, in case of failure, the person is likely to feel very incompetent (Schwebel et al., 2016). It should be emphasized that this orientation has influence on the personal interpretation of competence in various fields, such as sports activities (Hein \& Hagger, 2007). Just as there are different achievement goal orientations, which can be classified on the basis of ego and mastery, there is also a situational climate, which can be classified similarly. Both ego and mastery climates are influenced by interaction of personal and situational factors (O'Rourke et al., 2014). Parents and coaches can be named as individuals influencing youth sport socialization, who have an undeniable impact on children's psychosocial development (Pomerantz \& Thompson, 2008). As a result, the created microclimate can strongly influence children's achievement goal orientation (McArdle \& Duda, 2002).

SDT explains how satisfying the natural human innate extrinsic motivation of psychological needs (relatedness, competence, autonomy) becomes intrinsic, and how this transformation can be promoted and maintained (Deci \& Ryan, 2000). In SDT, in accordance with the motive autonomy and values internalization, extrinsic motivation is divided into four levels: external regulation (controlled by external incentives or penalties), introjected regulation (values are taken over from the environment, but are not yet perceived as one's personal self, associated with the ego, when any motivation to act leads to desire pride, or fault avoidance), identified regulation (indicates a conscious personal choice of goals and its perception as personally important) and integrated regulation (with the highest level of autonomy and is perceived when certain values are assimilated with one's personal self, and are intertwined with other values, objectives and desires). Essential SDT principle states that personal motivation control takes place through environmental social context (Deci \& Ryan, 1985), where interpersonal relationships with others (e.g. parents, teachers, coaches and other authoritative persons) play a major role (Fenton, Duda \& Barrett, 2016). When the microclimate created by these people encourages 
athletes' relatedness, competence, autonomy, the last-mentioned manifest higher forms of internal motivation (Amorose \& Anderson-Butcher, 2007). By analogy, when the above mentioned requirements are not satisfied, athletes experience a lower quality and more controlled motivation forms (Pelletier, Fortier, Vallerand, \& Brière, 2001). From the perspective of SDT, motivation in sports is a complicated and complex phenomenon because people have many motives to get involved in sports activities (Richard \& Edward, 2017), and athlete's psychosocial state during the process is strongly influenced by the approach and behaviour of the significant individuals surrounding them.

Both theories are closely correlated, and in some researchers' (Hein \& Hagger, 2007; Keshtidar \& Behzadnia, 2017; Standage, Duda, \& Ntnoumanis, 2003) opinion, they define the same things but in different aspects. For example, what is known as internal motivation in AGT correlates very well with the orientation to the task. By analogy, what is called extrinsic motivation in self-determination theory is well-connected with the orientation to the ego. The authors of these theories agree that both theories are in favour of actions and strategies that promote engagement in the task, whilst reducing the ego functioning (Spray, Wang, Biddle, \& Chatzisarantis, 2006). The very involvement in the task is likely to foster intrinsic motivation.

Parental role in children's sports activities. Parental involvement in children's sports activities was one of the most attractive research areas in the eighties (Clarke \& Harwood, 2014; Elliott \& Drummond, 2015), but interest in the subject increased greatly in recent years, when sports has become one of the most affordable and common leisure activities. However, the expression of youth's anti-social behaviour in social life has become a source of concern. The importance of teaching parents certain behaviour patterns is emphasized as research shows that certain parental behaviour can adversely affect children and adolescents' well-being and motivation to do sports (Elliott \& Drummond, 2016; Leo et al., 2015; Wiersma \& Fifer, 2008). According to Elliott and Drummond (2016), research community has been focused on parents' behaviour, such as abuse, criticism, coercion, which potentially makes a negative impact on young people, but little is known about the socially constructed meaning of parental verbal behaviour.

It is believed that the positive parent reinforcement is associated with children's, engaged in sports, satisfaction (Chan et al., 2011; Elliott \& Drummond, 2016; Elliott \& Drummond, 2015), higher self-esteem (Elliott \& Drummond, 2015; Schwebel et al., 2016), benevolence, competence, and, in some cases, elite status (Fraser-Thomas, Cote, \& Deakin, 2008; McCarthy, Jones \& ClarkCarter, 2008). It was found that parents' encouragement, praise and support increase children's awareness of their athletic ability systematically and have a positive impact on their interest in sports (Lavoie \& Stellino, 2008). When analysing the role of parents in children's activities, it is important to separate the influence of fathers and mothers which often can vary significantly. According to Brustad, Babkes, and Smith (2001), children can treat parents' behaviour differently. Differential perceptions of mothers' and fathers' influence appear to vary depending on the specific dimension or type of parental influence assessed (Lavoie \& Stellino, 2008).

The authors argue that the children's, engaged in sports, perception of father and mother's pressures, expectations and their impact on a variety of different sports results vary. Research results by Chan et al. (2011) show that mother's punishment, far more than father's, is related to children's, engaged in sports activities, anxiety. Lavoie and Stellino's (2008) study complements to the idea stating that mother's involvement in sports activities, far more than father's, is connected with the athletes' graciousness. However, only fathers' more active involvement in children's sports activities could decrease children's whining and complaining. Also, the authors argue that learning and enjoyment climate created by mothers, unlike fathers, is significantly negatively associated with children's, engaged in sports, tendency to play and talk tough. Meanwhile it is agreed unequivocally that those athletes who are included in the mastery climate are much less likely to behave in an antisocial manner (Leo et al. 2015; Palou, Vidal, Borràs, \& Garcia-Mas, 2013; Sanchez-Olivia, Leo, Sánchez-Miguel, Amado, \& García-Calvo, 2012). In addition, Miller and co-authors' (2005) research shows that players who are characterized by a high-performance climate respect social norms and rules less, as compared with those athletes who are characterized by low-performance climate. Danioni, Barn, and Rosnaili (2017) found that parental involvement in children's sportive activity turned out to be a significant predictor of adolescents' sport value acceptance, and 
this involvement was mainly characterized by encouragement (namely, praise and understanding) and only moderately by a directive behaviour or by active involvement. It should be noted that the participants of the research were characterized by much higher achievement values than status values. This can be interpreted that a strong sense of support for children engaged in sports inhibits their ego and promotes task orientation, resulting in the need for a natural result of their efforts to achieve the objectives without trying to compete with rivals and to gain a certain status. Research shows that those athletes who are involved in the mastery climate are much less likely to behave in an anti-social manner (Palou et al., 2013; SanchezOlivia et al., 2012). However, does parents' positive reinforcement always have a positive effect on children's behaviour?

The study by Leo et al. (2015) shows that parental support was not negatively associated with antisocial intention and judgment, and even antisocial performance correlated positively with parents' support. Lavoie and Stellino's (2008) research results show that both father's and mother's expectations and created concerning conducive climate is significantly associated with child's, engaged in sports activity, tendency to play and talk tough, as well as whine and complain. Côté \& Hay (2002) argue that too low or too high parental expectations can suppress any child's motivation and enthusiasm to be engaged in sports activities.

Taking into account aforementioned literature facts, it should be emphasized that parental involvement in children's sports activities can be described as a complex and dynamic process of interaction between parents and children, parents and coaches, depending on parents' empathy, game-like situation, children's performances and parents' knowledge and acquired experience (Holt, Temminen, Black, Sehn, \& Wall, 2008).

\section{CONCLUSION}

This work aimed at revealing parental role in children's sports activities, based on SelfDetermination and Goal Achievement theories. Systematic literature analysis showed that both theories are in favour of actions and strategy by which parents should encourage children's engaged in sports involvement in a task, reducing their ego manifestation. Looking at the abovementioned research, we can conclude that parents perceive their behaviour differently than that of children, so often parents' positive reinforcement can have a negative impact on children's, engaged in sports, psychosocial state, and later, on their values and goal-setting behaviour at present time and in the future. Undoubtedly parents play an important role in children's sports activities, but researchers produce controversial results without being able to unequivocally answer why parents' behaviour is caused by different reactions and how these reactions affect children's psychosocial state. Finally, while we now have a better understanding of the impact of parents on young athletes' wellbeing, further research is warranted on areas, such as athletes' age and type of sport. Thus, this area still requires more in-depth research.

\section{REFERENCES}

Amorose, A. J., \& Anderson-Butcher, D. (2007). Autonomy-supportive coaching and self-determined motivation in high school and colleague athletes: A test of self-determination theory. Psychology of Sport and Exercise, 8, 657-670. doi: 10.1016/j.psychsport. 2006.11.003

Brustad, R. J., Babkes, M. L., \& Smith, A. L. (2001). Youth in sport: Psychological considerations. In R. N. Singer, H. A. Hausenblas, \& C. M. Janelle (Eds.), Handbook of sport psychology (2nd ed., pp. 604-635). New York: Wiley. Canadian Soccer Association. Retrieved from http://www.canadasoccer.com/eng/docs/ CCCReport.pdfS

Chan, D. K., Lonsdale, C., \& Fung, H. H. (2011). Influences of coaches, parents, and peers on the motivational patterns of child and adolescent athletes.
Scandinavian Journal of Medicine and Science in Sports, 22(4), 558-568, doi: 10.1111/j.1600-0838.2010.01277.x Clarke, N. J., \& Harwood, C. G. (2014). Parenting experiences in elite youth football: A phenomenological study. Psychology of Sport and Exercise, 15(5), 528537. doi:10.1016/j.psychsport.2014.05.004

Côté, J., Hay, J. (2002). Family influences on youth sport performance and participation. In J. M. Silva \& D. Stevens (Eds.), Psychological foundations of sport (pp. 503-519). Boston, MA: Allyn \& Bacon.

Danioni, F., Barni, D., \& Rosnati, R. (2017). Transmitting sport values: the importance of parental involvement in children's sport activity. Europe's Journal of Psychology, 13(1), 75-92. doi: 10.5964/ejop.v13i1.1265

Deci, E. L., Ryan, R. M. (1985). Intrinsic motivation and self-determination in human behavior. New York: Plenum. 
Deci, E. L., \& Ryan, R. M. (2000). The "what" and "why" of goal pursuits: Human needs and the selfdetermination of behavior. Psychological Inquiry, 11, 227-268.

Elliott, S. K., \& Drummond, M. J. N. (2016). During play, the break, and the drive home: The meaning of parental verbal behaviour in youth sport. Leisure Studies. doi: 10.1080/02614367.2016.1250804

Elliot, S. K., \& Drummond, M. J. N. (2015). The (limited) impact of sport policy on parental behaviour in youth sport: A qualitative inquiry in junior Australian football. International Journal of Sport Policy and Politics, 7(4), 519-530, doi: 10.1080/19406940.2014.971850

Fenton, S. A. M., Duda, J. L., \& Barrett, T. (2016). Optimising physical activity engagement during youth sport: A self-determination theory approach. Journal of Sports Sciences, 34(19), 1-11. doi: 10.1080/02640414.2016.1142104

Fraser-Thomas, J., Côté, J., \& Deakin, J. (2008). Understanding dropout and prolonged engagement in adolescent competitive sport. Psychology of Sport and Exercise, 9(5), 645-662. doi: 10.1016/j. psychsport.2007.08.003

Hein, V., \& Hagger M. S. (2007). Global self-esteem, goal achievement orientations, and self-determined behavioural regulations in a physical education setting. Journal of Sports Sciences, 25(2), 149-159. doi: $10.1080 / 02640410600598315$

Holt, N. L., Temminen, K. A., Black, D. E., Sehn, Z. L., \& Wall, M. P. (2008). Parental involvement in competitive youth sport settings. Psychology of Sport and Exercise, 9, 663-685. doi: 10.1016/j.psychsport.2007.08.001

Keshtidar, M., Behzadnia, B. (2017). Prediction of intention to continue sport in athlete students: A selfdetermination theory approach. PLoS ONE 12(2): e0171673. doi: 10.1371/journal. pone.0171673

Knight, C. J., Dorsch, T. E., Osai, K. V., Haderlie, K. L., \& Sellers, P. A. (2016). Influences on parental involvement in youth sport. Sport, Exercise, and Performance Psychology, 5(2), 161-178. http://dx.doi.org/10.1037/spy0000053

Lavoie, N. M., \& Stellino, M. B. (2008) The relation between perceived parent-created sport climate and competitive male youth hockey players' good and poor sport behaviors. The Journal of Psychology, 142(5), 471-496. doi: 10.3200/JRLP.142.5.471-496

Leo, F. M., Sánchez-Miguel, P. A., Sánchez-Olivia, D., Amado, A., \& Garcia-Calvo, T. (2015). Motivational climate created by other significant actors and antisocial behaviors in youth sport. Kinesiology, 47(1), 3-10.

McArdle, S., \& Duda, J. K. (2002). Implications of the motivational climate in youth sports. In F. L. Smoll and R. E. Smith (Eds.), Children and Youth in Sport: A Biopsychosocial Perspective (pp. 409-434), Kendall/ Hunt, Dubuque, Iowa, USA.

McCarthy, P. J., Jones, M. V., \& Clark-Carter, D. (2008). Understanding enjoymentinyouth sport:Adevelopmental perspective. Psychology of Sport and Exercise, 9, 142156. doi: 10.1016/j.psychsport.2007.01.005
Miller, B. W., Roberts, G. C., \& Ommundsen, Y. (2005). Effect of perceived motivational climate on moral functioning, team moral atmosphere perceptions, and the legitimacy of intentionally injurious acts among competitive youth football players. Psychology of Sport and Exercise, 6, 461-477.

Nicholls, J. G. (1989). The competitive ethos and democratic education. Cambridge, Mass: Harvard University Press.

O`Rourke, D. J., Smith, R. E., Smoll, F. L., \& Cumming, S. P. (2014). Relations of parent - and coach-initiated motivational climates to young athletes' elf-esteem, performance anxiety, and autonomous motivation: Who is more influential? Journal of Applied Sport Psychology, 26(4), 395-408. http://dx.doi.org/10.1080/1041320 0.2014 .907838

Palou, P., Vidal, F. J. P. J. C. J., Cantallops, J., Borràs, P.A., \& Garcia-Mas, A. (2013). Acceptance of gamesmanship and cheating in young competitive athletes in relation to the motivational climate generated by parents and coaches. Perceptual and Motor Skills, 117, 290-303. http://dx.doi.org/10.2466\%2F10.30.PMS.117x14z9

Pelletier, L. G., Fortier, M. S., Vallerand, \& R. J., Brière, N. M. (2001). Associations among perceived autonomy support, forms of self-regulation, and persistence: A prospective study. Motivation and Emotion, 25, 279-306. doi: 10.1023/A:1014805132406

Pomerantz, E. M., \& Thompson, R. A. (2008). Parents' role in children's personality development: The psychological resource principle In John, O. P., Robins, R. W., Pervin, L. A (Eds.), Handbook of Personality: Theory and Research 3 (pp. 351-374). New York, USA: Guilford.

Richard, M. R, \& Edward, L. D. (2017). Self-determination theory: basic psychological needs in motivation, development and wellness. New York: Guilford.

Sánchez-Oliva, D., Leo, F. M., Sánchez-Miguel, P. A., Amado, D., \& García-Calvo, T. (2012). Antecedentes motivacionales de los comportamientos prosociales $\mathrm{y}$ antisociales en el contexto deportivo. [Motivational antecedents of prosocial and antisocial behaviors in a sport context. In Spanish.] Revista Internacional de Medicina y Ciencias de la Actividad Física y el Deporte, 12, 253-270.

Schwebel, F. J., Smith, R. E., \& Smoll, F. L. (2016). Measurement of perceived parental success standards in sport and relations with athletes' self-esteem, performance anxiety, and achievement goal orientation: Comparing parental and coach influences. Child Development Research, Article ID 7056075. doi: http:// dx.doi.org/10.1155/2016/7056075

Shields, D. L., \& Bredemeier, B. L. (2007). Advances in sport morality research. In Tenenbaum, G., Eklund, R. C. (Eds.), Handbook of sport psychology (3rd ed.), (pp. 662-684). Indianapolis, IN: Wiley.

Spray, C. M., Wang, C K. J., Biddle, S. J. H., \& Chatzisarantis, N. L. D. (2006). Understanding motivation in sport: An experimental test of achieve- 
ment goal and self-determination theories. European Journal of Sport Science, 6(1), 43-51. doi: 10.1080/17461390500422879

Standage, M., Duda, J. L., \& Ntoumanis, N. A. (2003). Model of contextual motivation in physical education: Using constructs from self-determination and achievement goal theories to predict physical activity intentions. Journal of Educational Psychology, 95(1) 97-110. http://dx.doi.org/10.1037/0022-0663.95.1.97

Stefansen, K., Smethe, I., \& Strandbu, A. (2016). Understanding the increase in parents' involvement in organized youth sports. Sport, Education and Society, 1-11. doi: http://dx.doi.org/10.1080/13573322.2016.1150834

Timperio, A. F., van Stralen, M. M., Brug, J., Bere, E., Chinapaw, M. J., de Bourdeaudhuij, I., ... te Velde, S. J. (2013). Direct and indirect associations between the family physical activity environment and sports participation among 10-12 year-old European children: Testing the EnRG framework in the ENERGY project. The International Journal of Behavioral Nutrition and Physical Activity, 10, 1-10. doi: 10.1186/1479-586810-15

Wiersma, L. D., \& Fifer, A. M. (2008). The schedule has been tough but we think it's worth it: The joys, challenges, and recommendations of youth sport parents. Journal of Leisure Research, 40(4), 505-530.

Wheeler, S. (2012). The significance of family culture for sports participation. International Review for the Sociology of Sport, 47(2), 235-252. doi: 10.1177/1012690211403196

Yesu, L., \& Harwood, E. A. (2015). The effects of parental involvement, support, and pressure on athletic participation. Rivier Academic Journal, 11(1), 1-11. 